\title{
Reappraisal of the Canadian Critical Care Society's position on withholding and withdrawing life-sustaining treatment
}

\author{
Greg Yanke, JD, MBA, MSBA (D) Mohamed Y. Rady, BChir, MB (Cantab), MA, MD (Cantab), FRCS, FRCP \\ (UK), FCCM • Joseph L. Verheijde, PhD, MBA, PT
}

Received: 18 January 2018/ Accepted: 19 February 2018/Published online: 16 March 2018

(c) Canadian Anesthesiologists' Society 2018

\section{To the Editor,}

As Canadian courts and healthcare facilities grapple with the legal and ethical issues arising from recent brain death cases, the Canadian Critical Care Society's (CCCS) recent position paper on withholding and withdrawing lifesustaining treatment (WWLST) is very timely. ${ }^{1}$ Given the emotional nature of end-of-life decisions and the potential for disagreements between healthcare providers (HCPs) and substitute decision-makers (SDMs) to emerge, the authors' emphasis on communication and making efforts to understand patient values is laudable. Nevertheless, while the CCCS acknowledges that HCPs should recognize the diversity of multicultural values that impact attitudes towards WWLST, ultimately the CCCS implies that existing medical standards should take precedence over patient wishes. This attitude is especially clear when the authors acknowledge that Section 2 of the Charter of Rights and Freedoms protects a patient's freedom of conscience and religion yet dismiss this constitutional

This letter is accompanied by a reply. Please see Can J Anesth 2018; 65: this issue.

G. Yanke, JD, MBA, MSBA ( $\square)$

School of Historical, Philosophical, and Religious Studies, Arizona State University, Tempe, AZ, USA

e-mail: Gregory.Yanke@asu.edu

M. Y. Rady, BChir, MB (Cantab), MA, MD (Cantab), FRCS, FRCP (UK), FCCM

Department of Critical Care Medicine, Mayo Clinic College of

Medicine and Science, Mayo Clinic Hospital, Phoenix, AZ, USA

J. L. Verheijde, PhD, MBA, PT

Department of Physical Medicine and Rehabilitation, Mayo

Clinic College of Medicine and Science, Mayo Clinic,

Scottsdale, AZ, USA protection when it is "extrapolated to protecting demands that are inconsistent with medical or secular standards". ${ }^{1}$

Section 2 of the Charter is meant to protect the beliefs of minority groups that do not share the values that underlie the secular standards that the policies of government institutions often reflect. Although it may be unreasonable to require HCPs to defer to such beliefs when they obviously contradict medical realities, medical judgments often include implicit value assumptions. The authors make the statement that life-sustaining treatments should be discontinued when "the healthcare team assesses that there is no realistic prospect of a meaningful [our emphasis] recovery" ${ }^{1}$ Nevertheless, embedded in this claim is a judgment regarding what level of human functioning is valuable, which transcends medical diagnosis or prognosis. Similarly, in the academic discourse concerning brain death, when practitioners were forced to acknowledge that biological death and brain death are not synonymous in the face of evidence that the body's integrated functions are not brain mediated, ${ }^{2}$ some attempted to overcome this reality by responding that the brain-dead patient is "as good as dead". As we have argued elsewhere, ${ }^{3}$ this is a normative assertion based on a value assessment and is not exclusively in the domain of medical expertise. In such situations, as a tolerant society, we should accept different conceptions of what constitutes a valuable life, including religious and secular views that hold that life does not cease until cardiopulmonary death.

While the CCCS laments the fact that the Supreme Court of Canada, in Cuthbertson v. Rasouli, 2013 S.C.C. 53 [2013] 3 S.C.R., failed to completely clarify the role of consent regarding WWLST, any pronouncements that the Court made beyond the purview of the case would have been considered dicta and would have been inappropriate without a specific factual context. What the Court did 
clarify is that the decision to withdraw life-sustaining treatment does constitute treatment as the Ontario Health Care Consent Act (HCCA), 1996, SO 1996, c. 2, Sched. A., broadly defines it. As well, the Court appropriately held that a physician cannot unilaterally withdraw lifesustaining treatment given a patient's autonomy interests. The physician must instead convince the Consent and Capacity Board that the SDM was not acting either in accordance with the patient's most recent wishes or, if unknown, what would be in his or her best interests, which HCCA ss. 21(2)(a) states may be properly based on the patient's known values and beliefs. Clearly, under the current legal regime, medical and secular standards are not the final arbitrator in the decision to withdraw lifesustaining treatment.

Conflicts of interest None declared.
Editorial responsibility This submission was handled by Dr. Hilary P. Grocott, Editor-in-Chief, Canadian Journal of Anesthesia.

\section{References}

1. Canadian Critical Care Society Ethics Committee; Bandrauk N, Downar J, Paunovic B. Withholding and withdrawing lifesustaining treatment: The Canadian Critical Care Society position paper. Can J Anesth 2018; 65: 105-22.

2. Shewmon DA. The brain and somatic integration: Insights into the standard biological rationale for equating 'brain death' with death. J Med Philos 2001; 26: 457-78.

3. Yanke G, Rady MY, Verheijde JL. When brain death belies belief. J Relig Health 2016; 55: 2199-213. 